\title{
Characterization of Peat Microbial Functional Diversity in Aerobic Rice Rhizosphere
}

\author{
Nor Ayshah Alia Ali Hassan ${ }^{1 *}$ and Halimi Mohd Saud ${ }^{2}$ \\ ${ }^{1}$ Soil Science, Water and Fertilizer, Malaysian Agricultural Research and Development Institute, MARDI \\ Headquarters, Persiaran MARDI-UPM, 43400 Serdang, Selangor, Malaysia \\ ${ }^{2}$ Department of Agriculture Technology, Faculty of Agriculture, Universiti Putra Malaysia, 43400 Serdang, \\ Selangor, Malaysia
}

\begin{abstract}
Microorganisms in the rhizosphere possess numerous metabolic activities. The addition of inorganic substance such as fertilizer could affect the microbial functional diversity. This study was conducted to evaluate the effect of different rate of NPK fertilizer on microbial functional diversity in the rhizosphere of local aerobic rice variety. Aerobic rice variety MRIA 1 was used in this study. Peat was taken from a non-agricultural area in Klang, Malaysia. The effect of fertilizer rate was determined with 4 different rates $(\mathrm{C}=$ nonfertilized; T1 = 100 kg/ha NPK; T2 = 200 kg/ha NPK; T3 = $400 \mathrm{~kg} / \mathrm{ha} \mathrm{NPK).} \mathrm{Microbial}$ functional diversity was performed using Biolog ${ }^{\mathrm{TM}}$ Ecoplate System and measured by microbial activities, such as average well color development (AWCD), species richness $(R)$, Shannon-Weaver index ( $H$ index) and species evenness $(E)$. As a result, microbial activity increased to $5.7 \%$ when fertilizer applied at T2, while fertilizer rate at T3 increased species richness by $3.2 \%$. However, addition of fertilizer did not affect the $H$ index while species evenness slightly decreased by $1.1 \%$

ARTICLE INFO

Article history:

Received: 13 May 2020

Accepted: 8 October 2020

Published: 27 November 2020

DOI: https://doi.org/10.47836/pjtas.43.4.18

E-mail addresses:

ayshalia@mardi.gov.my (Nor Ayshah Alia Ali Hassan)

halimi@upm.edu.my (Halimi Mohd Saud)

*Corresponding author

when applied at T3. Bacteria population was reduced when fertilizer added at $\mathrm{T} 1$. Fertilizer addition to the peat soil decreased the culturable population of nitrogenfixing microbes while no effect was found on culturable fungal, actinomycetes and phosphate-solubilizing microbe population. Microbes in T2 utilized many carbon
\end{abstract}


sources. Variation in carbon sources used by microbes was found when fertilizer was applied at different rates. D-cellobiose, pyruvic acid methyl ester, and L-serine were the carbon sources that influenced the microbial function in soil. It is concluded that fertilizer has an effect on microbial functional diversity in the peat rhizosphere of local aerobic variety. The recommended fertilizer rate (T2) increased the microbial activity while high fertilizer rate (T3) increased species richness and decreased species evenness.

Keywords: Carbon source, fertilizer, microbial functional diversity, rhizosphere

\section{INTRODUCTION}

Fertilizer is one of essential component for agricultural crop production. The acidification of soil and nutrients disparity was among the bad effects of high amount of fertilizer in soil. Nitrogen and phosphorus in fertilizer could affect the functional diversity and community structure of rhizosphere microorganisms, which play a vital role in plant growth and soil fertility (Dotaniya \& Meena, 2015). A decrease in microbial community due to inorganic disturbance such as fertilizer could potentially limit the services that they provide for the soil and plant. Therefore, it is important to study how microbial community in the rhizosphere responds towards environmental changes. Rhizosphere has been regarded as a remarkable ecosystem because microorganisms inhabited this area showed a variety of metabolic activities (Saleem, 2015). Microorganisms in rhizosphere are capable to do vast functions, for instance, constructing below and above multitrophic interactions and nutrient cycling covering different trophic levels.

To date, there is inadequate microorganism research in aerobic rice. Prior studies on aerobic rice only emphasized on useful microorganism for enhancing plant growth and as soil enrichment (Nahi et al., 2016; Nasarudin et al., 2018). On the other hand, constant flooding and raised water inputs are needed in the usual paddy rice field. These will be challenging since it is predicted that economic water insufficiency will affect 22 million irrigated dry-season rice in Southeast Asia by 2025 (Tuong \& Bouman, 2003). Henceforth, aerobic rice was initiated to preserve and improve water use efficiency. The trait from lowland and upland rice were integrated to produce aerobic rice (Tuong \& Bouman, 2003), which can be grown in non-flooded fields with additional irrigation and high input. Researches on microbial community using restriction fragment length polymorphism were already performed (Sutradhar, 2015; Vishwakarma \& Dubey, 2019). However, to our knowledge, there is no study on the response of microbial functional diversity towards fertilizer specifically in local aerobic rice. The response of microbial functional diversity towards fertilizer is important because as mentioned earlier microbes play a vital role in plant growth and soil fertility. Microbial functional diversity reflects genetic diversity (Carolina, 
2018) and it is important to determine the analytical level of diversity to sustain ecosystem function from disturbances. Aerobic rice is a potential crop for future food production. The ability of aerobic rice to grow in non-saturated condition is suitable to address water scarcity which is beneficial for food security. Thus, this study was conducted with the objective to evaluate the effect of NPK fertilizer on microbial functional diversity in the rhizosphere of local aerobic rice variety using the Biolog ${ }^{\mathrm{TM}}$ Ecoplate System.

\section{MATERIALS AND METHOD \\ Experimental Design}

This study was carried out in the glasshouse at the Malaysian Agricultural Research and Development Institute (MARDI). The temperature of the glasshouse when the study was conducted was $32{ }^{\circ} \mathrm{C}$. MRIA 1 was selected for aerobic rice variety and was planted in a planter box $(620 \mathrm{~mm} \mathrm{x}$ $230 \mathrm{~mm}$ x $188 \mathrm{~mm}$ ). Peat soil was selected because aerobic rice was previously being planted in peat areas in order to test the planting suitability of aerobic rice MRIA 1 (Othman et al., 2014). Peat was taken from a non-agricultural area in Klang, Malaysia. The peat is classified as hemic and collected from an oligotrophic area. A total of 4 planter boxes used for each fertilizer rate representing 4 replicates. Each planter box was planted with 5 aerobic rice and composite as 1 replicate. The experiment was arranged in a randomized complete block design (RCBD).
A standard manual by Othman (2013) was adapted for the growth of aerobic rice. Prior to planting, soil was prepared using rack, shovel, and trowel. Aerobic rice seed germination was performed by soaking the seeds in tap water for 24 hours. The seed were sown with the rate of $130 \mathrm{~kg} / \mathrm{ha}$ using the dry direct seeding method. Each seed was sown with the distance between $25 \mathrm{~cm}$. The NPK compound fertilizer rate used for aerobic rice is 150:60:60 kg/ha of N, $\mathrm{P}_{2} \mathrm{O}_{5}$, and $\mathrm{K}_{2} \mathrm{O}$ (Othman, 2013). The application of compound fertilizer was done at 5 days, 25 days, and 45 days after sowing. The optimum water depth for soil watering was $40 \mathrm{~mm}$ which occured during the vegetative stage. The effect of fertilizer rate was determined with 4 different rates as follows:
a. non-fertilized (control)
b. $100 \mathrm{~kg} / \mathrm{ha}$ NPK compound fertilizer (T1)
c. $200 \mathrm{~kg} / \mathrm{ha}$ NPK compound fertilizer, recommended dosage (T2)
d. $400 \mathrm{~kg} / \mathrm{ha}$ NPK compound fertilizer (T3)

\section{Soil Sampling}

Rhizosphere was collected during the mature stage of aerobic rice growth, which was after 90 days of sowing. The soil strongly adhered to the roots after gentle shaking was considered as rhizosphere soil.

\section{Soil Properties}

A standard method by Chapman and Pratt (1978) was used for measuring soil $\mathrm{pH}$ 
in soil/water extract with the ratio of 1:10. Cation exchange capacity (CEC) was performed according to the proposed method by Harada and Inoko (1980). The determination of soluble phosphorus was performed according to Bray and Kurtz (1945). A total of $2 \mathrm{~g}$ of soil was added to $20 \mathrm{ml}$ of extracting solution which consisted of $\mathrm{NH}_{4} \mathrm{~F}$ and $\mathrm{HCl}$ to remove soluble phosphorus. Flow injection analyzer (Lachat Instruments, USA) was used to measure CEC and soluble phosphorus. Total carbon and total nitrogen were measured according to the combustion method (Lagen, 1996) by using elemental analyzer (Flash 2000, Thermo Scientific, USA).

\section{Microbial Functional Diversity Analysis}

Microbial functional diversity was evaluated by measuring the microbial activity and community level physiological profile. Biolog Ecoplate ${ }^{\mathrm{TM}}$ system was used to assess these two criteria. The Biolog Ecoplate ${ }^{\mathrm{TM}}$ consists of 31 different carbon sources pertinent to ecosystem. A metabolic fingerprint was produced from the interaction between the microbial community and carbon sources (Garland, 1997). Soil suspensions (soil $100 \mathrm{~g}$ to 1 litre of distilled water) were agitated for $30 \mathrm{~min}$ followed by filtration using 0.45 $\mu \mathrm{m}$ filter paper. A total of $100 \mu \mathrm{l}$ aliquots were inoculated in the Ecoplate ${ }^{\mathrm{TM}}$ and incubated at $27^{\circ} \mathrm{C}$. The consumption of carbon source by microbes resulted in cell respiration and thus reduces tetrazolium dye to purple color. Color intensity in each well was recorded as optical density (OD) at $590 \mathrm{~nm}$ wavelength. To ensure that only carbon source-use response was obtained, the OD was measured at 48 hours to allow the microbial usage of any soluble organic carbon obtained from the rhizosphere (Gomez et al., 2006).

\section{Microbial Activity}

Average well color development was validated by measuring the OD values (590 $\mathrm{nm})$ after 48 hours of incubation. Average well color development was calculated as follows (Gomez et al., 2006):

$$
\mathrm{AWCD}=\sum \mathrm{OD}_{\mathrm{i}} / 31
$$

where, $\mathrm{OD}_{\mathrm{i}}$ is the optical density value from each Ecoplate ${ }^{\mathrm{TM}}$ well.

\section{Community-level Physiological Profile}

Community-level physiological profile was determined by assessing the richness $(R)$, Shannon diversity index $(H)$, and Shannon evenness (E) (Garland, 1997). The values were calculated from the OD values of Ecoplate wells incubated at 48 hours. Richness was determined as the total number of oxidized carbon substrates (Biolog EcoPlate ${ }^{\mathrm{TM}}$ well with $\mathrm{OD} \geq 0.25$ as threshold for positive response of oxidized carbon substrates). Shannon diversity index was calculated as follows:

$$
H=\Sigma p_{i}\left(\ln p_{i}\right)
$$

where, $p_{i}$ is the ratio of the activity on each substrate $\left(\mathrm{OD}_{\mathrm{i}}\right)$ to the sum of activities on all substrates $\left(\Sigma O D_{\mathrm{i}}\right)$ in 
Biolog EcoPlate ${ }^{\mathrm{TM}}$ well whereas $\ln$ is the natural logarithm.

Shannon evenness was examined from the value of $H$ and $R$ (Zak et al., 1994) and calculated as follows:

$$
E=H / \ln R
$$

\section{Carbon Source Utilization}

The utilization of carbon source of microbes was measured using OD in Ecoplate well after 48 hours of incubation. Carbon source in Ecoplate was categorized into 5 guilds as according to Weber and Legge (2009).

\section{Enumeration of Culturable Microorganism}

Total plate count was used to evaluate culturable aerobic microorganism. The abundance of bacteria, fungi, actinomycetes, nitrogen-fixing microbes and phosphatesolubilizing microbes were measured by using nutrient agar (NA), potato dextrose agar (PDA), starch casein agar (SCA), Burks's agar (NF), and Pikovskaya's agar (PKA), respectively. Nutrient agar and PDA were prepared as specified by the manufacturer (Merck, Germany). Burk's agar, PKA, and SCA were prepared as according to Ali Hassan et al. (2019). A total of $10 \mathrm{~g}$ of soil was added into $90 \mathrm{ml}$ of sterile distilled water to create a soil suspension. A tenfold dilution series was performed on the soil suspension and aliquots of $1 \mathrm{ml}$ were inoculated on selective media and incubated at $27^{\circ} \mathrm{C}$ for 48 hours for NA and PDA while NF, PKA, and SCA were incubated for 168 hours (7 days). Colony forming unit (CFU) was used to quantify total plate count and expressed as $\log _{10} \mathrm{CFU} / \mathrm{ml}$.

\section{Statistical Analysis}

Analysis of variance (ANOVA) and multiple comparisons of means Fisher's least significant difference (LSD) test were used for the interpretation of AWCD, $R, H$, $E$, and aerobic culturable microorganism. The amount of change in AWCD, $R, H$, $E$, and aerobic culturable microorganism were calculated using the percentage of change. Principal component analysis was performed for substrates in Ecoplate ${ }^{\mathrm{TM}}$ well. All statistical analyses were performed with Minitab 17.

\section{RESULT AND DISCUSSION}

\section{Soil Properties}

The average of total carbon, total nitrogen, total and soluble phosphorus, CEC and $\mathrm{pH}$ were $45.09 \%, 2.36 \%, 853.87 \mathrm{ppm}$, $57.35 \mathrm{ppm}, 75.57 \mathrm{meq} / 100 \mathrm{~g}$, and 4.91, respectively (Table 1). Fertilizer that was applied at 50\% lower than recommended rate (T1) increased the total nitrogen. This indicates that fertilizer application at 100\% recommended rate (T2) and high rate (T3) can decrease total nitrogen and this might be explained by high nitrogen mineralization. A previous study had shown that the addition of high NPK fertilizer could cause high nitrogen mineralization in peat (Maftu'ah et al., 2019).

However, total carbon, total phosphorus, and CEC were increased when fertilizer was 
applied at 50\% lower than the recommended rate (T1) and at $100 \%$ recommended rate (T2). This indicates that excessive fertilizer (T3) reduces total phosphorus in peat that might be caused by the low capacity of peat organic colloid to adsorb phosphorus (Ahmad et al., 2013). Prior study had shown that high amount of inorganic fertilizer reduced the soil CEC (Zhang et al., 2017). The decrease of CEC might be explained by the enhanced of the soil organic matter decomposition when high NPK fertilizer was applied as demonstrated by previous research (Bhatt et al., 2019).

Table 1

Soil chemical properties

\begin{tabular}{lllllll}
\hline $\begin{array}{l}\text { Fertilizer } \\
\text { rate }\end{array}$ & $\begin{array}{l}\mathrm{TC} \\
(\%)\end{array}$ & $\begin{array}{l}\mathrm{TN} \\
(\%)\end{array}$ & $\begin{array}{l}\text { TP } \\
(\mathrm{ppm})\end{array}$ & $\begin{array}{l}\text { SP } \\
(\mathrm{ppm})\end{array}$ & $\begin{array}{l}\text { CEC } \\
(\mathrm{meq} / 100 \mathrm{~g})\end{array}$ & $\mathrm{pH}$ \\
\hline $\mathrm{C}$ & $37.08 \mathrm{c}$ & $1.77 \mathrm{c}$ & $598.51 \mathrm{c}$ & $50.5 \mathrm{c}$ & $67.88 \mathrm{c}$ & $4.54 \mathrm{c}$ \\
$\mathrm{T} 1$ & $51.16 \mathrm{a}$ & $2.68 \mathrm{a}$ & $847.25 \mathrm{~b}$ & $65.9 \mathrm{~b}$ & $70.11 \mathrm{~b}$ & $4.86 \mathrm{~b}$ \\
$\mathrm{~T} 2$ & $39.01 \mathrm{~b}$ & $2.03 \mathrm{~b}$ & $860.48 \mathrm{a}$ & $48.8 \mathrm{~d}$ & $81.02 \mathrm{a}$ & $4.96 \mathrm{a}$ \\
$\mathrm{T} 3$ & $24.34 \mathrm{~d}$ & $1.42 \mathrm{~d}$ & $581.89 \mathrm{~d}$ & $74.7 \mathrm{a}$ & $60.86 \mathrm{~d}$ & $4.96 \mathrm{a}$ \\
\hline
\end{tabular}

Note. CEC $=$ Cation exchange capacity; $\mathrm{SP}=$ Soluble phosphorus; $\mathrm{TC}=$ Total carbon; $\mathrm{TN}=$ Total nitrogen; $\mathrm{TP}=$ Total phosphorus. Mean separation of soil chemical properties using Fisher's least significant difference. Mean in each column with the same letter is not significantly different $(p \leq 0.05)$ among the fertilizer rate

Table 1 shows that the addition of fertilizer from $\mathrm{T} 1$ and $\mathrm{T} 3$ had increased the $\mathrm{pH}$ from 4.54 (non-fertilized) to 4.96 (heavily fertilized). The increase in $\mathrm{pH}$ will result in a conducive environment for microbial population as more microbes that prefer $\mathrm{pH} 5$ and above may thrive in this condition as compared to lower $\mathrm{pH}$ condition. Earlier studies have shown that $\mathrm{pH}$ is the main driver of microbial diversity (Ren et al., 2018; Too et al., 2018).

Apart from that, it can be deduced from the results of total carbon and nitrogen that the $\mathrm{C} / \mathrm{N}$ ratio was the lowest in $\mathrm{T} 3$ (17.14) and the highest in $C$ (20.9) due to no addition of nitrogen from fertilizer was incorporated into the soil in C. According to previous studies (Chen et al., 2014; Leifeld et al., 2020), a C/ $\mathrm{N}$ ratio of less than 25 will result in decomposition to proceed at maximum rate under suitable environmental condition. It is noted that high fertilizer (T3) reduced almost all of the selected soil chemical properties (total carbon, nitrogen, phosphorus, and CEC) compared to other treatments.

\section{Microbial Activity}

The ability of microbes to use specified substrate in Biolog Ecoplate is expressed as AWCD and can be applied as microbial activity. Microbial activity was increased to $5.7 \%$ when fertilizer was applied at the 
recommended rate (Figure 1). Figure 1 shows that microbial activity was higher in T2 and T3 compared to $\mathrm{C}$ and T1. This suggests that the addition of NPK fertilizer increased the activity of microbes in peat soil. Such finding is supported by the results in soil chemical properties where at the highest rate of fertilizer application most of the soil chemical properties were reduced.

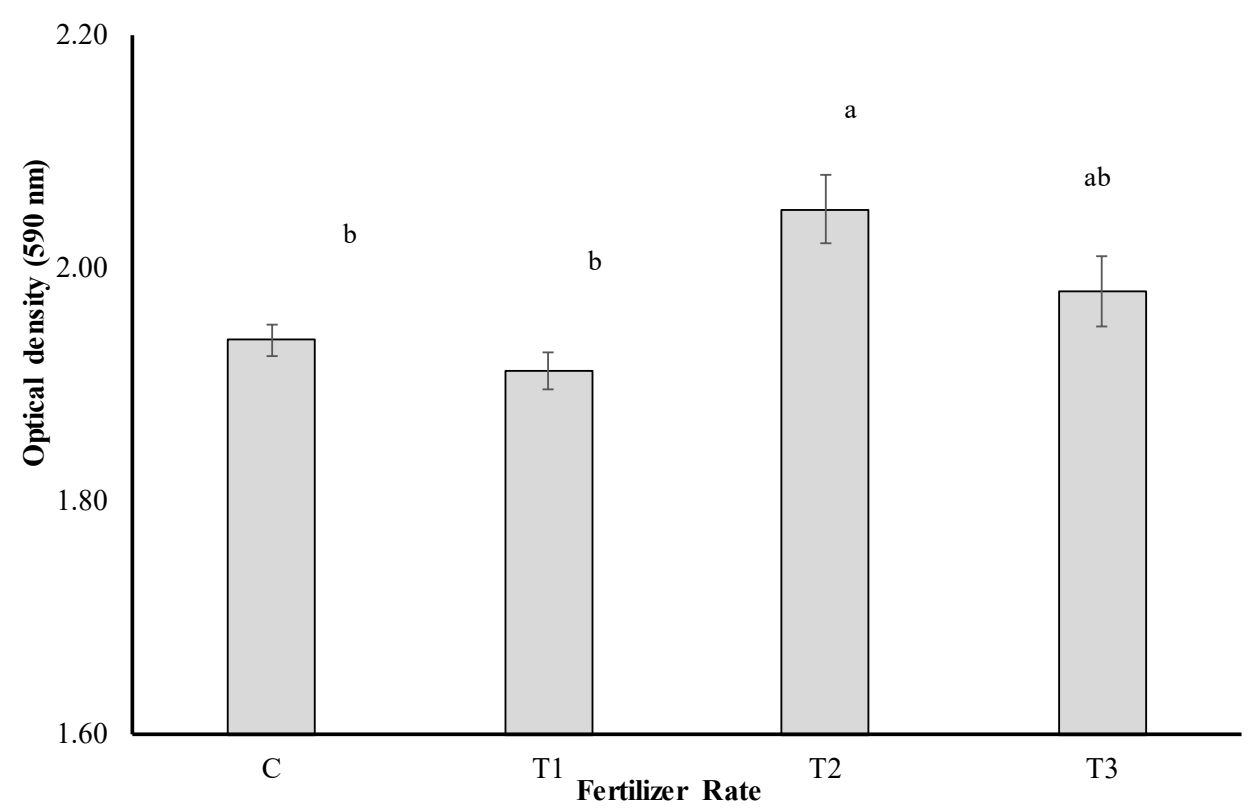

Figure 1. Microbial activity in peat

Furthermore, this result also justified by the data in soil chemical properties where at higher rate of fertilizer application, $\mathrm{C} / \mathrm{N}$ ratio was reduced. Thus, this led to decomposition process resulting in higher microbial activity.

\section{Community-level Physiological Profile}

Figure 2a illustrates that high fertilizer rate (T3) increased peat species richness by $3.2 \%$. The addition of fertilizer rate of T3 might increase microorganisms that were able to adapt to the new rhizosphere environment.
For example, based on the results of soil properties, total nitrogen was reduced at T3 indicated that high nitrogen mineralization might occur. A previous report showed that archaea were significantly involved the nitrogen mineralization in peat soil (Espenberg et al., 2018). This might explain on the increase of species richness.

Shannon-Weaver index ( $H$ index) was used to measured catabolic diversity. It was noted that fertilizer did not affect the $H$ index (Figure 2b) while Figure 2c showed that microbial evenness was slightly decreased 
by $1.1 \%$ when applied to highest fertilizer rate (T3). Although species evenness was reduced, the increase in richness managed to elevate microbial activity and thus not affecting the catabolic diversity. Species that had been elevated was able to perform catabolic function in peat. The slight decrease of species evenness at T3 might be caused by the increase of specific microorganisms that favored this environment. The results from soil chemical properties showed that most of the soil chemical properties were reduced at $\mathrm{T} 3$. This indicated that there were microorganisms that reduced and became dormant while there are others that were enhanced from these conditions thus decreasing the species evenness.

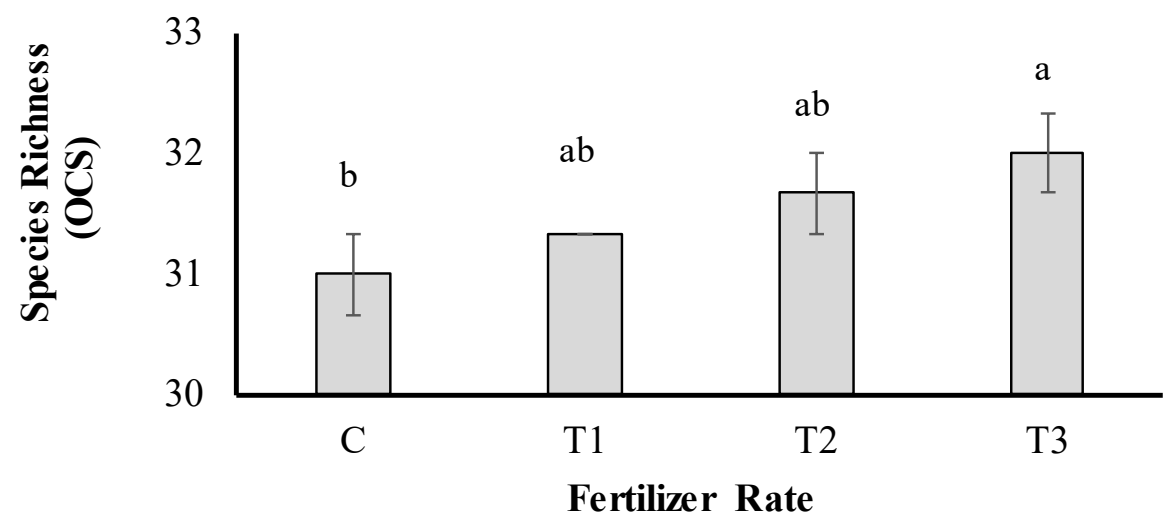

(a)

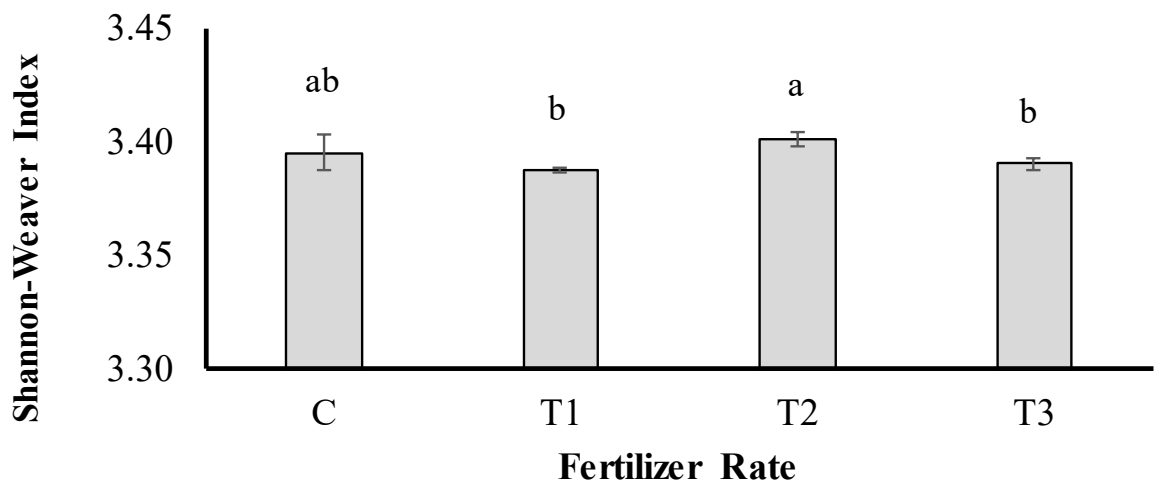

(b)

Figure 2. Community-level physiological profile in peat is evaluated by measuring (a) species richness, (b) Shannon-Weaver index, and (c) Shannon evenness. Mean separation of community-level physiological profile using Fisher's least significant difference. Mean in each column chart with the same letter is not significantly different $(p \leq 0.05)$ among the fertilizer rate 


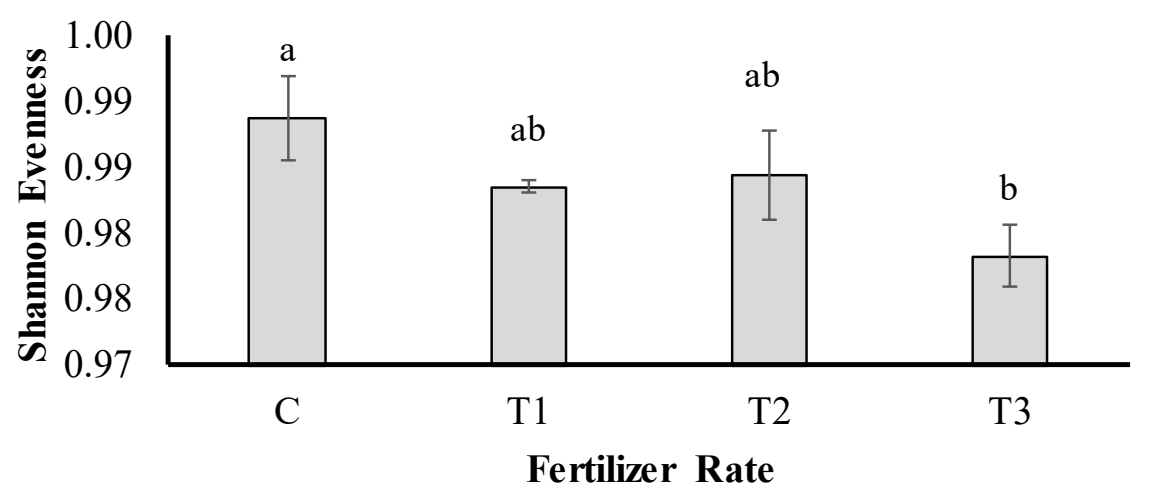

(c)

Figure 2. (Continued)

Note. OCS $=$ Total number of oxidized carbon substrate

Microbial functional diversity was characterized by measuring the microbial activity and community-level physiological profile (species richness, catabolic diversity, and microbial evenness). Microbial activity in peat was increased when added with recommended fertilizer rate (T2). Species richness was elevated with excessive fertilizer application (T3). Fertilizer addition reduced species evenness but did not influence their catabolic diversity. These results indicate that microbial functional diversity in peat was enhanced with the addition of fertilizer rate tested in this study.

\section{Carbon Source Utilization}

Figure 3 shows that fertilizer application did not influence the consumption of carbohydrates by microorganisms. This indicates that the rhizosphere microorganisms in non-fertilized and fertilized peat utilized many of the given carbohydrates and might explained on the insignificant effect of fertilizer towards carbohydrate consumption. A recent study by Tang et al. (2020) had demonstrated that carbohydrates were the main carbon source that was utilized by rhizosphere microorganism. In peat soil, carbohydrates are involved in peat formation and act as an indicator for organic matter reactivity for humification (Hodgkins et al., 2018), which showed the importance of carbohydrate in peat. Thus, although there was a difference in soil chemical properties, microorganisms that were able to use carbohydrates were still present in the rhizosphere.

However, the utilization of amines and amides as well as amino acid was increased after fertilizer (T1, T2, and T3) was applied compared to non-fertilized peat (C). Numerous studies have shown that the free pool of amino acids is small in soil (Hu et al., 2017; Warren, 2014). The addition of fertilizer might increase the amino acid and amines in the rhizosphere and this 
enhanced microorganisms that prefer amino acid and amines as their substrates for growth. Amino acid and amines are known to be involved in microbial metabolism as two of the main nitrogen sources for soil microorganisms which may explain the increased consumption of these two groups by microorganisms.

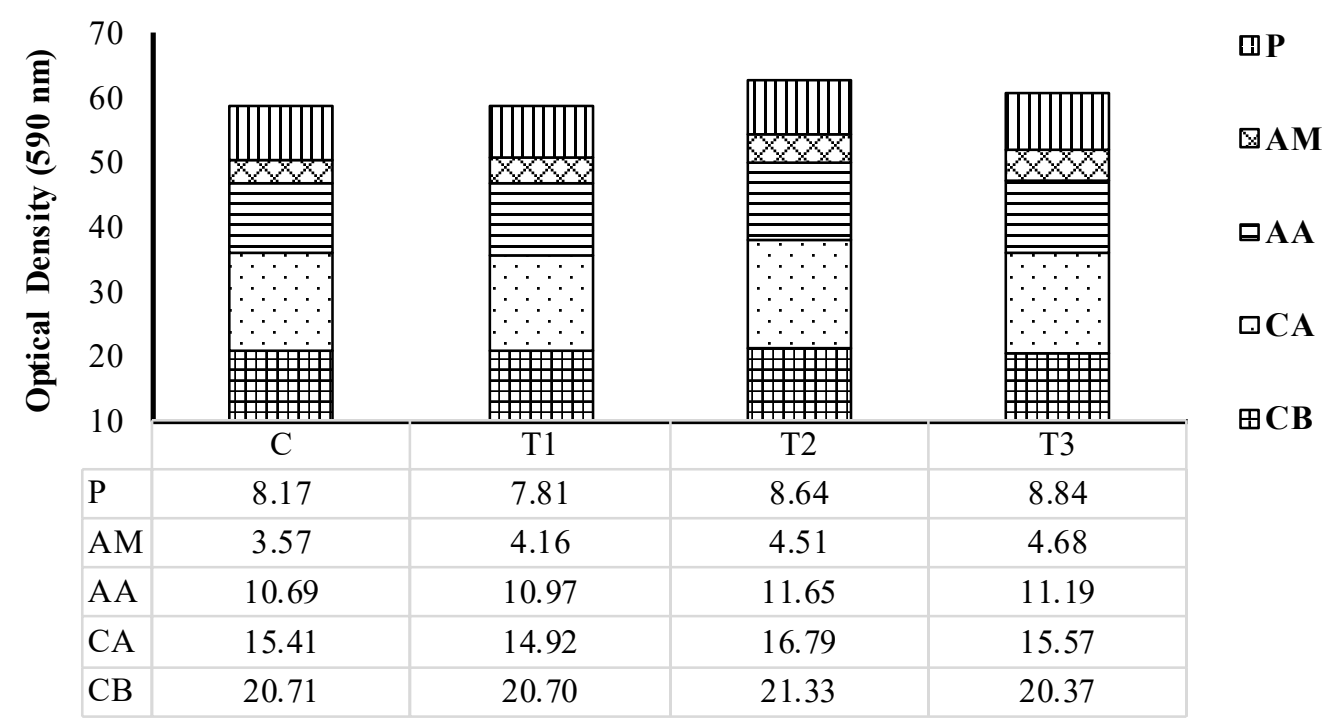

Fertilizer Rate

Figure 3. Carbon source utilization in peat

Note. $\mathrm{P}=$ Polymer; $\mathrm{AM}=$ Amines and amides $; \mathrm{AA}=$ Amino acid $\mathrm{CA}=$ Carboxylic and acetic acid; $\mathrm{CB}=$ Carbohydrate

It was noted that for total guild consumption, microbes in recommended fertilizer rate utilized the highest carbon sources. The effect of fertilizer on microbial consumption of total carbon source had the same pattern with catabolic diversity in community-level physiological profile. It was also observed that the total guild consumption coincided with their microbial activities. This shows that the recommended fertilizer rate has enriched the microbes that can utilize different types of carbon sources as shown by using Biolog. This scenario was expected since Biolog Ecoplate was used in the quantification of carbon source utilization.

The optical densities of 31 carbon sources from the rhizosphere at different fertilizer rate were used to create a heatmap (Figure 4). This study showed that microbes in non-fertilized peat $(C)$ were able to heavily utilize 7 carbon sources ( $\beta$-methyl- 
D-glucoside, pyruvic acid methyl ester, 4-hydroxybenzoic acid, L-serine, D-galacturonic acid, 4-hydroxybenzoic acid, N-acetyl-D-glucosamine, D-cellobiose, $\alpha$-cyclodextrin, $\mathrm{N}$-acetyl-D-glucosamine, and putrescine). Microbes was able to and D-glucosaminic acid). Microbes in consume 10 carbon sources when fertilizer low fertilizer rate (T1) heavily used 10 was added at recommended rate (T2) carbon sources $(\beta$-methyl-D-glucoside, (D-galactonic acid $\gamma$-lactone, L-arginine, D-galactonic acid $\gamma$-lactone, L-arginine, D-galacturonic acid, L-phenylalanine, D-galacturonic acid, D-mannitol, D-mannitol, 4-hydroxybenzoic acid,

Water

$\beta$-methyl-D-glucoside

D-galactonic acid $\gamma$-lactone

L-arginine

Pyruvic acid methyl ester

D-xylose

D-galacturonic acid

L-asparagine

Tween 40

i-Erythritol

2-hydroxybenzoic acid

L-phenylalanine

Tween 80

D-mannitol

4-hydroxybenzoic acid

L-serine

$\alpha$-cyclodextrin

$\mathrm{N}$-acetyl-D-glucosamine

$\gamma$ - hydroxybutyric acid

L-threonine

Glycogen

D-glucosaminic acid

Itaconic acid

Glycyl-L-glutamic acid

D-cellobiose

Glucose-1-phosphate

$\alpha$-ketobutyric acid

Phenylethylamine

$\alpha$-D-lactose

D, L- $\alpha$-glycerol phosphate

D-malic acid

Putrescine

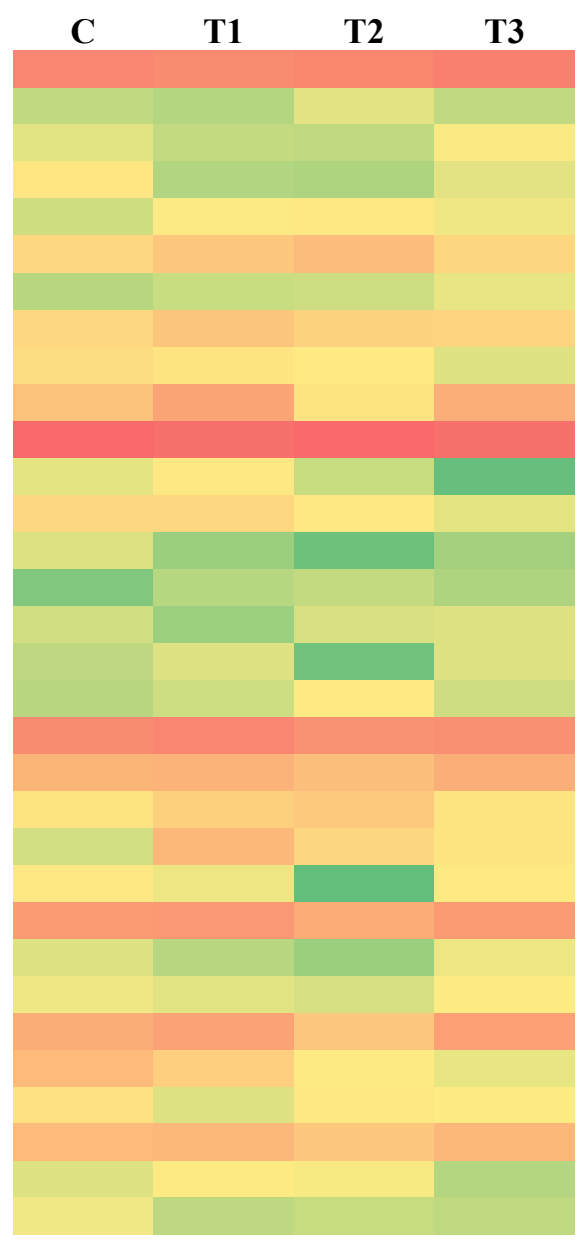

Optical Density

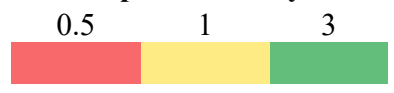

Figure 4. The heatmap of microbial communities from aerobic rice rhizosphere at different fertilizer rate depending on the carbon source utilization 
$\alpha$-cyclodextrin, itaconic acid, D-cellobiose, glucose-1-phosphate, and putrescine). A total of 7 carbon sources was heavily utilized by microbes in peat applied excessive fertilizer rate (T3) ( $\beta$-methyl-Dglucoside, L-phenylalanine, D-mannitol, 4-hydroxybenzoic acid, N-acetyl-Dglucosamine, D-malic acid, and putrescine). This study is in agreement with previous studies (Furtak et al., 2019; Li et al., 2018). These results suggested that there was variation in the carbon source consumption by the microbes at different fertilizer rate. The changes in soil properties after the addition of fertilizer could influence the microbial community.

The principal component analysis was conducted in which data is represented to reduce dimensionality while preserving the variance of the data. For peat, principal component one (PC1), principal component 2 (PC2), and principal component 3 (PC3) explained 51.0, 30.4, and $18.6 \%$ of the variation which corresponded to eigenvalues of $16.313,9.720$, and 5.967 , respectively (Table 2). A carbohydrate, D-cellobiose with coefficient 0.247 received the greatest weight in the PC1. For PC2, the greatest coefficient (0.310) occurred at pyruvic acid methyl ester, followed by 4-hydroxybenzoic acid, N-acetyl-D-glucosamine, L-arginine, and putrescine with coefficients greater than 0.25 . L-serine had the greatest weight in PC3 (-0.370), followed by L-asparagine, i-Erythritol, $\beta$-methyl-D-glucoside, $\alpha$-D-lactose, D-glucosaminic acid, and $\alpha$-cyclodextrin. The greatest factors contributing to $\mathrm{PC} 1, \mathrm{PC} 2$, and $\mathrm{PC} 3$ in peat were mainly carbohydrates.

Principal component analysis revealed that soil microbial communities in peat utilized mostly carbohydrates. D-cellobiose which has greatest contribution in PC1 is a major carbon source for soil bacterial communities (Schellenberger et al., 2011). Cellulose is a biopolymer that is easily available due to its abundance in peat soil, since peat is formed by partially and completely decayed plant materials that by nature contain high amounts of cellulose. Hence, microbes converted cellulose to cellobiose and later use it as a carbon source.

Table 2

Principal component 1, 2, and 3. Eigenvalues (including percentage of variation), substrates loaded in each $P C$, substrate type, and eigenvector for substrate in each PC obtained from Ecoplates in peat

\begin{tabular}{lllll}
\hline Component & Eigenvalue & Substrate & Type & Coefficient \\
\hline PC1 & $16.313(51.0 \%)$ & D-cellobiose & CB & -0.247 \\
PC2 & $9.720(30.4 \%)$ & Pyruvic acid methyl ester & CA & -0.310 \\
& & 4-hydroxybenzoic acid & CA & -0.306 \\
& & N-acetyl-D-glucosamine & CB & -0.284 \\
& & L-arginine & AA & 0.276 \\
& & Putrescine & AM & 0.265 \\
\hline
\end{tabular}


Table 2 (Continued)

\begin{tabular}{|c|c|c|c|c|}
\hline Component & Eigenvalue & Substrate & Type & Coefficient \\
\hline \multirow[t]{7}{*}{ PC3 } & $5.967(18.6 \%)$ & L-serine & AA & -0.370 \\
\hline & & L-asparagine & AA & 0.366 \\
\hline & & i-Erythritol & $\mathrm{CB}$ & 0.335 \\
\hline & & $\beta$-methyl-D-glucoside & $\mathrm{CB}$ & -0.324 \\
\hline & & $\alpha$-D-lactose & $\mathrm{CB}$ & -0.308 \\
\hline & & D-glucosaminic acid & $\mathrm{CA}$ & 0.300 \\
\hline & & $\alpha$-cyclodextrin & $\mathrm{P}$ & 0.293 \\
\hline
\end{tabular}

Note $. \mathrm{AA}=\mathrm{Amino}$ acid $\mathrm{AM}=$ Amines and amides $\mathrm{CA}=$ Carboxylic acid and acetic acid $\mathrm{CB}=\mathrm{Carbohydrates}$; $\mathrm{P}=$ Polymer

Pyruvic acid methyl ester which has the greatest contribution in PC2 is part of citric acid cycle which is important for generating energy for microbes. L-serine contributed largely in PC3 since this amino acid is plentiful in soil and involved in nitrogen metabolism (Pascual et al., 2016; Vranova et al., 2011). Carbohydrates explained the most variation in carbon source utilization in peat suggesting that microbial functional diversity was influenced by these carbohydrates particularly D-cellobiose, $\mathrm{N}$-acetyl-D-glucosamine, $\beta$-methyl-Dglucoside, i-Erythtritol, and $\alpha$-D-lactose.

\section{Population of Culturable Microorganism}

The population of culturable aerobic microorganism was measured using 5 different selective media. Bacteria population was reduced when fertilizer was added at lower rate (T1), but did not affect by other fertilizer rate (T2 and T3) applied (Table 3 ). This can be explained by the resilience ability possessed by soil bacteria. Prior study has demonstrated that soil bacteria were resilient to inorganic fertilizer disturbances (Čuhel et al., 2019).

Fertilizer did not have an effect on culturable fungal, actinomycetes and phosphate-solubilizing microbe population. Phosphate-solubilizing microbe population was not affected by the fertilizer because of the increase of soluble phosphorus in peat after fertilizer application. It is reported that plant growth reduced the relative abundance of Actinobacteria, Acidobacteria, and Firmicutes because of alteration in the rhizosphere (Shi et al., 2015). However, the increase in soluble phosphorus after fertilizer application could benefit these phyla and thus increase their proportion. The ability of Actinobacteria, Acidobacteria, and Firmicutes to solubilize phosphorus was reported in previous studies (Cao et al., 2018; Zheng et al., 2017, 2018).

The actinomycetes population in peat was not influenced by fertilizer addition when applied at different rates. Soil acidophilic actinomycetes such as Streptomyces genus 
were able to withstand soil chemical changes and thus might explained for the insignificant effect of fertilizer towards the population of actinomycetes. Earlier studies had shown that actinomycetes spores could be the factor for the resilience towards environmental changes (de Lima Procópio et al., 2012).

It was noted that fertilizer addition lowered the culturable population of nitrogen-fixing microbes in peat. This study measured free-living nitrogen-fixing microbes and it is known that these microbes require a low nitrogen environment to improve their activity (Wagner, 2011). Total nitrogen was increased with the addition of fertilizer and this could be the factor that contributes to the decrease of nitrogenfixing microbes in peat.

Table 3

Population of culturable aerobic microorganism

\begin{tabular}{llllll}
\hline $\begin{array}{l}\text { Fertilizer } \\
\text { Rate }\end{array}$ & $\begin{array}{l}\text { Bacteria } \\
\left(\log _{10} \mathrm{CFU} /\right. \\
\mathrm{ml})\end{array}$ & $\begin{array}{l}\text { Fungi } \\
\left(\log _{10} \mathrm{CFU} /\right. \\
\mathrm{ml})\end{array}$ & $\begin{array}{l}\text { Actinomycetes } \\
\left(\log _{10} \mathrm{CFU} /\right. \\
\mathrm{ml})\end{array}$ & $\begin{array}{l}\text { Nitrogen- } \\
\text { fixing } \\
\text { microbes } \\
\left(\log _{10} \mathrm{CFU} /\right.\end{array}$ & $\begin{array}{l}\text { Phosphate- } \\
\text { solubilizing } \\
\text { microbes } \\
\left(\log _{10} \mathrm{CFU} /\right. \\
\mathrm{ml})\end{array}$ \\
\hline $\mathrm{C}$ & $8.74 \pm 0.32 \mathrm{a}$ & $7.32 \pm 0.16 \mathrm{a}$ & $5.90 \pm 0.03 \mathrm{a}$ & $7.03 \pm 0.04 \mathrm{a}$ & $5.60 \pm 0.00 \mathrm{a}$ \\
$\mathrm{T} 1$ & $4.87 \pm 2.44 \mathrm{~b}$ & $7.10 \pm 0.10 \mathrm{a}$ & $6.01 \pm 0.15 \mathrm{a}$ & $6.26 \pm 0.19 \mathrm{~b}$ & $3.33 \pm 1.67 \mathrm{ab}$ \\
$\mathrm{T} 2$ & $7.20 \pm 0.20 \mathrm{ab}$ & $2.33 \pm 2.33 \mathrm{a}$ & $5.70 \pm 0.11 \mathrm{a}$ & $6.17 \pm 0.01 \mathrm{~b}$ & $3.75 \pm 1.88 \mathrm{ab}$ \\
$\mathrm{T} 3$ & $8.05 \pm 0.28 \mathrm{ab}$ & $4.67 \pm 2.33 \mathrm{a}$ & $6.18 \pm 0.06 \mathrm{a}$ & $6.39 \pm 0.13 \mathrm{~b}$ & $3.97 \pm 1.99 \mathrm{ab}$ \\
\hline
\end{tabular}

Note. Mean $\log _{10} \mathrm{CFU} / \mathrm{ml}$ measured based on different selective medium and data are expressed in means $\pm \mathrm{SE}$ (standard error). Mean comparison was performed using Fisher's least significant difference. Mean in each column with the same letter is not significantly different $(p \leq 0.05)$ among the fertilizer rate

\section{CONCLUSION}

It is concluded that fertilizer has an effect on microbial functional diversity in the peat rhizosphere of local aerobic variety. Certain species in microbial community such as actinomycetes were not affected while there were others such as nitrogen-fixing microbes that decreased to adapt to changes and thus maintain the microbial functional diversity. Microbial activity was enhanced when added with recommended fertilizer rate while species richness was elevated with excessive fertilizer application. Although fertilizer addition reduces species evenness, it did not influence the catabolic diversity. Microbial community treated with recommended fertilizer rate was able to utilize many carbon sources. There was variation in the carbon source consumption by the microbes at different fertilizer rate. 
D-cellobiose, pyruvic acid methyl ester, and L-serine were the carbon sources that influence the microbial function in soil.

\section{ACKNOWLEDGEMENTS}

The authors would like to thank the Ministry of Agriculture and Agro-based Industry for providing the public funding (21003001480001) to carry out the study.

\section{REFERENCES}

Ali Hassan, N. A. A., Othman, R., \& Sadi, T. (2019). The response of microbial community in aerobic rice rhizosphere that affected by various plant growth stages and soil types. Malaysian Journal of Microbiology, 15(4), 277-288. doi: 10.21161/ mjm. 191543

Bhatt, M. K., Labanya, R., \& Joshi, H. C. (2019). Influence of long-term chemical fertilizers and organic manures on soil fertility - A review. Universal Journal of Agricultural Research, 7(5), 177-188. doi: 10.13189/ujar.2019.070502

Bray, R. H., \& Kurtz, L. T. (1945). Determination of total, organic, and available forms of phosphorus in soils. Soil Science, 59(1), 39-45. doi: 10.1097/00010694-194501000-00006

Cao, Y., Fu, D., Liu, T., Guo, G., \& Hu, Z. (2018). Phosphorus solubilizing and releasing bacteria screening from the rhizosphere in a natural wetland. Water, 10(2), 195. doi: 10.3390/ w10020195

Carolina, Z. F. A. (2018). Microbial diversity: Genetic diversity Vs. Functional diversity. Journal of MicroBiology and Experimentation, 6(1), 00814. doi: 10.15406/jmen.2018.06.00184

Chapman, H. D., \& Pratt, P. F. (1978). Methods of analysis for soils, plants and waters. Oakland, USA: Priced Publication.
Chen, B., Liu, E., Tian, Q., Yan, C., \& Zhang, Y. (2014). Soil nitrogen dynamics and crop residues. A review. Agronomy for Sustainable Development, 34(2), 429-442. doi: 10.1007/ s13593-014-0207-8

Čuhel, J., Maly, S., \& Královec, J. (2019). Shifts and recovery of soil microbial communities in a 40-year field trial under mineral fertilization. PedoBiologia, 77, 150575. doi: 10.1016/j. pedobi.2019.150575

de Lima Procópio, R. E., da Silva, I. R., Martins, M. K., de Azevedo, J. L., \& de Araújo, J. M. (2012). Antibiotics produced by Streptomyces. The Brazilian Journal of Infectious Diseases, 16(5), 466-471. doi: 10.1016/j.bjid.2012.08.014

Dotaniya, M. L., \& Meena, V. (2015). Rhizosphere effect on nutrient availability in soil and its uptake by plants: A review. Proceedings of the National Academy of Sciences, India Section B: Biological Sciences, 85(1), 1-12. doi: 10.1007/ s40011-013-0297-0

Espenberg, M., Truu, M., Mander, U., Kasak, K., Nõlvak, H., Ligi, T., ... Truu, J. (2018). Differences in microbial community structure and nitrogen cycling in natural and drained tropical peatland soils. Scientific Reports, 8(1), 4742. doi: 10.1038/s41598-018-23032-y

Furtak, K., Grządziel, J., Galązka, A., \& Niedźwiecki, J. (2019). Analysis of soil properties, bacterial community composition, and metabolic diversity in fluvisols of a floodplain area. Sustainability, 11(14), 3929. doi: 10.3390/su11143929

Garland, J. (1997). Analysis and interpretation of community-level physiological profiles in microbial ecology. FEMS Microbiology Ecology, 24(4), 289-300. doi: 10.1111/j.1574-6941.1997. tb00446.x

Gomez, E., Ferreras, L., \& Toresani, S. (2006). Soil bacterial functional diversity as influenced by organic amendment application. Bioresource 
Technology, 97(13), 1484-1489. doi: 10.1016/j. biortech.2005.06.021

Harada, Y., \& Inoko, A. (1980). The measurement of the cation exchange capacity of composts for the estimation of the degree of maturity. Journal of Soil Science and Plant Nutrition, 26(1), 127-134. doi: 10.1080/00380768.1980.10433219

Hodgkins, S. B., Richardson, C. J., Dommain, R., Wang, H., Glaser, P. H., Verbeke, B., ... Chanton, J. P. (2018). Tropical peatland carbon storage linked to global latitudinal trends in peat recalcitrance. Retrieved April 02, 2020, from https://www.nature.com/articles/s41467018-06050-2

Hu, Y., Zheng, Q., \& Wanek, W. (2017). Flux analysis of free amino sugars and amino acids in soils by isotope tracing with a novel liquid chromatography/high resolution mass spectrometry platform. Analytical Chemistry, 89(17), 9192-9200. doi: 10.1021/acs. analchem. $7 \mathrm{~b} 01938$

Lagen, B. V. (1996). Soil analysis. In P. Buurman, B. van Lagen, \& E. J. Velthorst (Eds.), Manual for soil and water analysis (pp. 1-120). Leiden, Netherlands: Backhuys Publishers.

Leifeld, J., Klein, K., \& Wüst-Galley, C. (2020). Soil organic matter stoichiometry as indicator for peatland degradation. Retrieved April 02, from https://www.nature.com/articles/s41598020-64275-y
Li, L., Xu, M., Eyakub Ali, M., Zhang, W., Duan, Y., \& Li, D. (2018). Factors affecting soil microbial biomass and functional diversity with the application of organic amendments in three contrasting cropland soils during a field experiment. PLOS One, 13(9), e0203812. doi: 10.1371/journal.pone.0203812

Maftu'ah, E., Susilawati, A., \& Hayati, A. (2019). Effectiveness of ameliorant and fertilizer on improving soil fertility, growth and yields of red chili in degraded peatland. Retrieved April 02, 2020, from https://iopscience.iop.org/ article/10.1088/1755-1315/393/1/012011

Nahi, A., Othman, R., \& Omar, D. (2016). Effects of Sb16 bacterial strain and herbicides on endophytic bacterial populations and growth of aerobic rice. Plant Soil and Environment, 62(10), 453-459. doi: 10.17221/289/2016-PSE

Nasarudin, N. A., Mohamad, J., Ismail, S., \& Mispan, M. S. (2018). Effect of nitrogen, phosphorus and potassium (NPK) and bacterial bio-fertilizer on the antioxidant activity and chlorophyll content of aerobic rice. Molecules, 23, 55. doi: 10.3390/ molecules 23010055 